\title{
O TEATRO ÍDICHE NO BRASIL: ALGUMAS CONSIDERAÇÕES
}

\section{YIDDISH THEATER IN BRAZIL: SOME CONSIDERATIONS}

Berta Waldman*

Saul Kirschbaum**

\begin{abstract}
Resumo: Durante mais de meio século, o teatro ídiche teve intensa participação na vida dos imigrantes judeus que vieram para o Brasil fugindo das péssimas condições de vida no leste europeu. Instrumento de criação e manutenção de laços comunitários, de preservação de uma cultura deixada para trás nos países de origem, mecanismo de integração na cultura hegemônica local e possibilidade de dar continuidade a uma atividade política também interrompida, sua origem remonta à década de 1910, mas de fato ganhou momento nos anos 1920 e atingiu seu apogeu nas décadas de 1940 e 1950; não obstante, entrou em decadência nos anos 1960 e efetivamente desapareceu na década de 1970. Neste artigo, procuramos oferecer um panorama das atividades cênicas dos imigrantes judeus de fala ídiche, sua importância como dispositivo de preservação cultural e o papel que o teatro ídiche desempenhou no esforço de integração do grupo étnico na cultura brasileira, numa via de mão dupla; finalmente, oferecemos algumas reflexões sobre os fatores que provocaram e/ou aceleraram sua decadência e final extinção.
\end{abstract}

Palavras-chave: Teatro ídiche. Imigração judaica para o Brasil. Laços comunitários dos imigrantes judeus. Integração cultural.

\begin{abstract}
For more than half a century, Yiddish theater had an intense participation in the lives of Jewish immigrants who came to Brazil fleeing the terrible living conditions in Eastern Europe. Instrument for the creation and maintenance of community ties, for the preservation of a culture left behind in the countries of origin, a mechanism for integrating into the local hegemonic culture and the possibility of continuing a political activity that was also interrupted, its origin dates back to the $1910 \mathrm{~s}$, but it did gain momentum in the $1920 \mathrm{~s}$ and reached its peak in the 1940s and 1950s; nevertheless, it fell into decay in the 1960s and effectively disappeared in the 1970s. In this article, we seek to provide an overview of the scenic activities of Yiddishspeaking Jewish immigrants, their importance as a device for cultural preservation and the role that Yiddish theater played in the effort to integrate the ethnic group into Brazilian culture, in a two-way road; finally, we offer some reflections on the factors that caused and/or accelerated its decay and final extinction.
\end{abstract}

Keywords: Yiddish theater. Jewish immigration to Brazil. Community ties of Jewish immigrants.

\section{Introdução: panorama histórico do teatro ídiche em São Paulo}

A elaboração deste trabalho foi viabilizada pela disponibilidade de três fontes: 1) a abrangente pesquisa realizada pelo professor Nachman Falbel, publicada com o título Estrelas Errantes: memória do teatro ídiche no Brasil (Cotia: Ateliê Editorial, 2013), além de outras obras de sua autoria que fazem referência ao tema do teatro ídiche; 2) o apoio prestado pela Casa do Povo, por intermédio de Benjamin Seroussi, Eliana Martins, Hugueta Sendacz e Marina Sendacz ${ }^{1}$; por fim, 3) as entrevistas concedidas a Berta Waldman na década de 1980 por atores do teatro ídiche, residentes em São Paulo, Santos e Campinas, que resultaram na publicação em livro, O teatro ídiche em São Paulo: memória

\footnotetext{
* Professora de Literatura Brasileira e Teoria Literária na Unicamp, professora de Literatura Hebraica na USP, email: <bwaldman@usp.br>.

*** Doutor em Letras pela FFLCH/USP, pós-doutor pela Unicamp. Pesquisador independente, email: <saul.kirschbaum@gmail.com>.

${ }^{1}$ Hugueta Sendacz e sua filha Marina receberam os autores em 13 de janeiro de 2020 para uma ampla conversa sobre o teatro ídiche em São Paulo.
} 
(São Paulo: Casa Guilherme de Almeida: Annablume: 2010); a autora da obra assinala que alguns desses atores continuaram suas carreiras no teatro brasileiro, atuando em peças faladas em português.

Em vista das más condições a que os judeus foram submetidos na Europa oriental, particularmente na Polônia, no período entre as guerras mundiais, a imigração judaica para o Brasil sofreu um grande incremento ${ }^{2}$.

Shmuel Ettinger, por exemplo, em “The Modern Period”, observa que a Polônia, que perdera sua autonomia e fora desmembrada em consequência de derrotas militares no final do século dezoito ante a Rússia, a Prússia e a Áustria, foi reestabelecida como estado independente somente em 1919, após o término da Primeira Guerra Mundial. Apesar de cláusulas constitucionais - impostas pelas potências vitoriosas - garantirem os direitos das minorias, os judeus, dez porcento da população total, foram vítimas de pogroms, sofreram restrições de cidadania, dificilmente eram aceitos no serviço público; ainda que não tivessem seu acesso a instituições de ensino superior limitado por leis de numerus clausus, sua presença nestas instituições mostrou considerável decréscimo em consequência de ataques e discriminação contra os estudantes judeus. ${ }^{3}$

Muitos desses imigrantes vieram da Europa politizados, a maioria simpatizantes das ideias da esquerda, com experiência em militância operária socialista além de portadores de uma tradição cultural expressiva.

Aqui chegando, uma das primeiras preocupações dos imigrantes judeus foi dar continuidade às atividades sociais e culturais, como meio de preservação dos laços comunais e ponto de partida para retomar a militância polĩtica.

Como informa Hugueta Sendacz,

Nos anos vinte do século passado, com o maior afluxo ao Brasil de judeus da Europa Oriental, principalmente da Polônia, onde a vida cultural era extremamente desenvolvida, tanto na literatura como na música e no teatro, tornou-se uma necessidade a criação de um clube que congregasse essas pessoas e lhes permitisse continuar suas atividades sociais e culturais. ${ }^{4}$

Em São Paulo essa necessidade foi suprida pela fundação, em 1922, do clube Zukunft ("Futuro"), que após algum tempo (1925) mudou seu nome para Yugent Club ("Clube da Juventude"), com atividades culturais, sociais, esportivas e políticas.

Em 1937 fora criado, na França, o YKUF (Yidisher Kultur Farband - Associação de Cultura Judaica), frente judaica progressista com o objetivo de opor-se ao avanço da extrema direita na Europa; uma das linhas de trabalho adotadas pela entidade foi o estímulo a iniciativas culturais onde quer que houvesse uma comunidade judaica. Com esse propósito, desenvolveu uma seção de arte, um grupo de escritores, círculos de leitura e publicações ${ }^{5}$. Na década de 1940, o Yugent Club aderiu ao YKUF e, para marcar esse alinhamento, deliberou mudar seu nome para Centro Cultura e Progresso, adotando como missão homenagear os que morreram nos campos de concentração nazistas e criar um espaço que reunisse as mais variadas associações que tinham nascido aqui na luta internacional contra o fascismo ${ }^{6}$.

Em 1946, com o término da guerra, foi criado o ICIB (Instituto Cultural Israelita Brasileiro), que incorporou o Centro Cultura e Progresso; em 1953, com a inauguração do prédio onde funciona até hoje, o ICIB passou a ser conhecido como Casa do Povo.

\footnotetext{
${ }^{2}$ Entre 1926 e 1942, por exemplo, de um total de 754.554 indivíduos que emigraram para o Brasil 49.947, ou cerca de 6,6\%, eram judeus (LESSER, 1994, p. 316).

${ }^{3}$ ETTINGER, 1997, p. 955 ss.

${ }^{4}$ SENDACZ, Hugueta. Pequena trajetória do trabalho cultural, social e político realizado pelos dedicados imigrantes no Yugent Club, Dramkraiz, Centro de Cultura e Progresso, ICIB/Casa do Povo, inédito, p. 1.

${ }^{5}$ Disponível em: <https://en.wikipedia.org/wiki/Farband>. Acesso em: 26/03/2020.

${ }^{6}$ Disponível em: <https://casadopovo.org.br/sobre>. Acesso em: 26/03/2020.
} 
Neste processo, o teatro teve papel relevante, não só em São Paulo e Rio de Janeiro, mas também nas principais capitais onde se estabeleceram comunidades ashkenazitas. Como registra Jacó Guinsburg,

[d]esde a década de 1920, mas principalmente nos anos trinta e quarenta deste século, o público de imigrantes ashkenazitas pôde assistir às peças levadas não só por esporádicos conjuntos de atores profissionais fixados no Brasil ou pelas constantes tournées de artistas e companhias da Argentina, Estados Unidos e Europa. Na verdade, tão ou mais importante neste aspecto foi a contribuição de elencos filodramáticos que, no Rio de Janeiro, em São Paulo, no Recife, em Salvador, em Curitiba e em Porto Alegre encenaram numerosos textos do repertório teatral ídiche. ${ }^{7}$

As montagens teatrais começaram já na época do Yugent Club, com a criação do Dram kraiz ("Círculo dramático"), que desenvolveu atividade permanente e ininterrupta. Uma das primeiras peças de grande porte encenadas, em 1940, se chamava Oifshtand ("Revolta" ou "Levante"). Por falta de local próprio, a peça foi apresentada no Teatro Santana. Ainda nesta fase, foi montada a peça Dos Groisse Gevintz ("A Sorte Grande"), de Scholem Aleichem, também no Teatro Santana. A peça Di Tzvei Kune-Leml ("Os dois Kune-Leml”), de Avrum Goldfadn, foi apresentada no teatro LusoBrasileiro. Em 1944, o Círculo Dramático teve acesso ao Teatro Municipal, onde encenou O Inspetor Geral, de Gogol, Motke ganef ("Motke, o ladrão"), de Scholem Asch, e Uriel Acosta, de Karl Guskov.

Outra grande realização do Dram kraiz, no final de 1947, início de 1948, foi a montagem da opereta Goldfadn Cholem ("O sonho de Goldfaden"), de autoria de Jacob Rotbaum, que veio a São Paulo para dirigir esse espetáculo, depois de tê-lo apresentado em Paris e Buenos Aires ${ }^{8}$. Esta peça, na sequência, foi apresentada em Belo Horizonte, Salvador, Porto Alegre e outras cidades.

Durante a guerra e no imediato pós-guerra muitas das peças encenadas pelo Dram kraiz tinham como tema o repúdio ao nazi-fascismo, às atrocidades nazistas e à guerra.

Outras atividades desenvolvidas pelo Yugent incluiram a fundação, em 1935, de um Coro que se manteve ativo até 1970.

Em 1960 foi concluída a construção do TAIB $^{9}$ - Teatro de Arte Israelita Brasileiro, que recebeu o subsolo do prédio da Casa do Povo. O prédio abrigou várias outras atividades, entre as quais o Ginásio Israelita Brasileiro Scholem Aleichem, grupos de leitura, biblioteca, o clubinho Kinderland, reuniões do comitê editorial do jornal Nossa Voz, associações de bairro e o Teatro Popular do SESI. Nas décadas de 1950 e 1960, algumas peças encenadas pelo TAIB expandiram o tratamento da temática social para além do universo judaico.

Ainda antes do final da construção do TAIB, um grupo de jovens ligados ao ICIB fundou o Teatro da Juventude, com o objetivo de fazer teatro de vanguarda. Em 1956, por exemplo, o grupo montou a peça Bolingbrok \& Cia. ou As casadas solteiras, de Martins Pena, que participou do 3o Festival de Teatro Amador de São Paulo. Neste evento, conquistaram dois Arlequins: o prêmio de Melhor Ator e o de Melhor Coadjuvante Masculino. No início alugavam teatro, figurino, cenários e adereços.

No Festival do ano seguinte, nova participação com a peça Histórias para serem contadas, de autoria do dramaturgo argentino Osvaldo Dragun, resultou na conquista do Arlequim de Melhor Atriz.

Os atores do teatro ídiche eram amadores; o contato com profissionais se dava de duas maneiras: os atores eram voluntários mas o diretor era remunerado; isto se tornou possível porque durante a Guerra vieram da Europa vários atores e diretores profissionais; ou então, quando companhias profissionais se apresentavam em São Paulo - o que era frequente, indo para ou voltando de Buenos Aires -, agregavam amadores locais para completar os elencos.

\footnotetext{
${ }^{7}$ GUINSBURG, 1996, p. 444-445.

${ }^{8}$ GOUSSINSKY, 2012, p. 193.

${ }^{9}$ Henrique Veltman observa que, não por acaso, “taib” significa "pomba” em ídiche, o que seria uma franca alusão à pomba da paz de Picasso (VELTMAN, 1994, p. 77).
} 
Em outra iniciativa, o ICIB criou o Teatro Escola com o qual colaboraram, com palestras, conferências, aulas e debates, destacados profissionais do mundo teatral brasileiro, como Gianfrancesco Guarnieri, Décio de Almeida Prado, Ruggero Jacobbi e Zbigniew Ziembinski.

A inauguração do TAIB foi marcada por diversos eventos, como concerto do Coral Scheiffer; peça apresentada pelo grupo teatral da juventude; outra pelo grupo teatral infantil; recital de piano; apresentação de coral falado; encenação do Dram kraiz; e montagem do Grupo Teatral do Clube I. L. Peretz.

Seguiu-se a montagem de várias peças importantes, como Schver tzu zain a id ("é difícil ser judeu"), de Scholem Aleichem, e $O$ dibuk, de An-Ski. Esta última contou com patrocínio da Comissão Estadual de Teatro.

Por motivos que analisaremos mais adiante, todos esses grupos acabaram por encerrar suas atividades. O teatro ídiche em São Paulo terminou na década de 1960. A última apresentação do Dram kraiz, da qual participaram também atores do Grupo de Teatro da Juventude, aconteceu em novembro de 1965, com a peça Di Ksube (“A certidão de casamento"), de Efraim Kishon. Após esse evento, o grupo se dissolveu.

\section{Teatro: instrumento de preservação cultural de uma comunidade de imigrantes}

Em muitos países de acolhimento, comunidades de imigrantes formaram associações religiosas, culturais, esportivas, como mecanismos de preservação de suas identidades étnicas minoritárias. Afinal, a noção de comunidade é a cola que mantém unida uma cultura. Os que já exerciam atividades políticas ou culturais em seus países de origem buscaram continuar essas práticas junto aos demais imigrantes, criando sinagogas, bibliotecas, clubes sociais, grupos de teatro. ${ }^{10}$ Este fenômeno foi assinalado por Chaim Israel Jugend (Xuxe), em entrevista à revista "O Macabeu", publicada em Curitiba, em 1980:

É o seguinte: teatro sempre houve, teatro é uma coisa inerente ao povo judeu. Imigrando, transplantados para o Brasil, eles continuaram atentos às suas origens e às tradições aprendidas nas escolas judaicas, os cheder. [...] Fazer teatro era uma tradição. Eu me lembro em criança, na Europa, assistindo ao teatro que eles faziam. Eu devia ter 9 ou 10 anos de idade, e lembro que, com todas as dificuldades provindas da situação, eles faziam teatro. ${ }^{11}$

Isto é particularmente importante no caso dos judeus. Observe-se que ao contrário de imigrantes de outras origens étnicas, que tinham uma pátria para onde retornar se esse fosse seu desejo, poucos judeus tiveram essa oportunidade. Os judeus eram discriminados e acossados na terra em que nasceram, considerados ao mesmo tempo "de dentro" e "de fora" e transformados em alvo das ondas antissemitas que culminaram com o extermínio dos judeus ashkenazitas durante a Segunda Guerra Mundial. ${ }^{12}$

O vínculo entre imigração e atividade teatral - inclusive com suas conexões internacionais é enfatizada por Nachman Falbel com as seguintes palavras:

A década de 1920, que se caracteriza pelo aumento da imigração judaica ao Brasil e a solidificação de suas instituições comunitárias, representa uma nova etapa na história do teatro ídiche no país e se destaca como um período em que é "descoberto"

\footnotetext{
${ }^{10}$ Em relação à atividade política exercida por imigrantes, Jacó Guinsburg observa que "uma parte da história da esquerda brasileira, principalmente em São Paulo, no Rio de Janeiro, Rio Grande do Sul, Pernambuco e Bahia, foi escrita por militantes originários da imigração, ou seja, italianos, espanhóis, portugueses, judeus e lituanos". Apud WALDMAN, 2010, p. 27.

${ }^{11}$ Apud SCHULMAN, 2011, p. 121.

${ }^{12}$ WALDMAN, 2010, p. 43.
} 
pelas trupes e atores do exterior e no qual se encontram empresários que promovem o teatro profissional. ${ }^{13}$

De fato, nesta época o teatro ídiche, que se difundira nas comunidades brasileiras, tornara-se agora entretenimento popular para o crescente número de imigrantes que chegaram após o término da Primeira Guerra Mundial e mais intensivamente a partir de meados dos anos $1920 .{ }^{14}$

Este crescimento pode ser evidenciado através das seguintes cifras: de 1901 a 1920 chegaram ao Brasil 10.750 judeus, ou 537,5 por ano; de 1921 a 1925, este número subiu para 7.139, média de $1.427,8$ por ano; e de 1926 a 1930 houve um salto para 22.296 indivíduos, 4.459,2 por ano. ${ }^{15}$

O crescimento da população judaica e a prosperidade obtida na década de 1930, juntamente com a atuação de empresários e instituições comunitárias, permitiram que a sucessão de atoresvisitantes fosse contínua. ${ }^{16}$

A criação de entidades com o objetivo de viabilizar a preservação da cultura de origem e a solidariedade grupal pode ser observada em muitas cidades brasileiras.

Em entrevista a Berta Waldman, Bóris Cipes, um dos imigrantes que atuou no teatro ídiche, reporta que "quando chegamos em Campinas, a primeira coisa que fizemos foi organizar uma biblioteca de 600 livros e um teatro com palco". ${ }^{17}$

No Rio de Janeiro, para Paula Ribeiro, "o teatro ídiche, as operetas musicais, a organização de corais, as noites literárias com declamações podem ser consideradas uma forma de resistência cultural dos habitantes da Praça Onze". ${ }^{18}$

O mesmo fenômeno teve lugar em Belo Horizonte. Júlia Calvo observa, em sua dissertação de mestrado, que naquela cidade "a primeira instituição judaica foi criada em torno do elemento religioso (a União Israelita de Belo Horizonte, em 1922). Na instituição funcionava uma sinagoga e eram mantidas atividades culturais tais como uma biblioteca em ídiche, um clube de leitura e um grupo de teatro". ${ }^{19}$

Em Recife, Nachman Falbel destaca que Jacob Nachbin - que se estabeleceu naquela cidade em 1921 -, como parte de sua contribuição cultural em prol da comunidade judaica, organizou um grupo teatral em língua ídiche. ${ }^{20}$

A respeito de Porto Alegre, Falbel destaca a figura de José Schreiber que organizou grupos teatrais nas principais comunidades judaicas do Rio de Janeiro, São Paulo, Curitiba e Porto Alegre; e também que no âmbito do Centro Israelita jovens formaram um conjunto de amadores de teatro e se uniram ao grupo pré-existente, organizando espetáculos beneficientes. ${ }^{21}$

Em Niterói, conforme Andréa Telo da Côrte,

[o] cotidiano da juventude progressista judaica era dividido entre as discussões literárias e políticas, os ensaios de teatro, do coral e a frequência ao cineclube, onde filmes europeus eram apresentados seguidos de debates. Dentre as peças apresentadas pela biblioteca destaque-se a representação anual do Levante do Gueto de Varsóvia, evento constante do calendário da instituição. [...] Em Kinderland, colônia de férias localizada em Vassouras, os jovens progressistas de todo o Brasil

\footnotetext{
${ }^{13}$ FALBEL, 2013, p. 143.

${ }^{14}$ FALBEL, 2013, p. 143.

${ }^{15}$ LESSER, 1995, p. 316.

${ }^{16}$ FALBEL, 2013, p. 169. Na década de 1930, na verdade, houve redução nos números da imigração judaica, devido, talvez, às restrições impostas pelo regime de Getúlio Vargas, para o qual os judeus eram "indesejáveis" e politicamente perigosos. Em relação a esse estado de coisas, ver $O$ antissemitismo na Era Vargas, de Maria Luiza Tucci Carneiro.

17 WALDMAN, 2010, p. 49.

${ }^{18}$ RIBEIRO, 2008, p. 227.

${ }^{19}$ CALVO, 2014, p. 108.

${ }^{20}$ FALBEL, 1984, p. 189

${ }^{21}$ FALBEL, 2008, p. 721 ss.
} 
se encontravam, atividades teatrais eram estimuladas, assim como a frequência ao Clube I. L. Peretz. ${ }^{22}$

Também a retomada da atividade política, que era frequente na Europa oriental de origem, não se deu de forma casual. Na grande emigração que se seguiu aos pogroms de Kishinev (1903; 1905), boa parte da liderança do Bund $d^{23}$ acompanhou os emigrantes, exatamente com a intenção de manter o trabalho político de educação das massas, sindicalização, etc. ${ }^{24}$ Muitos dos militantes judeus que vieram para o Brasil eram membros do Bund ou dos partidos comunistas de seus locais de origem. A escolha do ídiche como língua de expressão na atividade teatral não se deveu apenas ao fato de ser o idioma falado pelos imigrantes da Europa central. Na verdade, esta opção correspondeu a uma decisão estratégica adotada pelas instituições, que seguiram as linhas partidárias originárias na Europa - Bund, Linke-Poalei Zion -, que estabeleceram o ídiche como parte de sua plataforma ideológica. ${ }^{25}$

Isto é o que aconteceu no Zukunft, no Yugent, no Centro Cultura e Progresso e, por fim, no ICIB. Desde a inauguração de sua sede, a Casa do Povo, o ICIB acolheu o TAIB (Teatro de Arte Israelita Brasileiro), e também o GIBSA (Ginásio Israelita Brasileiro Scholem Aleichem), grupos de leitura, grupos de teatro amador, de teatro ídiche, de teatro juvenil, uma biblioteca, o clubinho Kinderland, e ainda, alinhando-se com as vanguardas da época, cedeu espaço para atividades que extrapolavam os interesses da comunidade judaica, como associações de bairro, o Teatro Popular do SESI, montagem de peças do Teatro de Arena, apresentação de peças de autores como Plínio Marcos, Gianfrancesco Guarnieri e Augusto Boal, shows do MPB4, aulas de Lygia Fagundes Telles, lançamentos de livros. ${ }^{26}$

Coerentemente com a orientação política dos dirigentes do ICIB, o TAIB, instalado no subsolo da Casa do Povo, privilegiou peças com fundo social e político, como Uriel Acosta ${ }^{27}$. Em geral, as peças elaboravam a vida nos guetos. Desde 1944, o ICIB estabeleceu uma comemoração anual da revolta do Gueto de Varsóvia.

Para aumentar seu espaço de atuação e aperfeiçoar seu desempenho, muitos de seus membros participaram, como coadjuvantes, das companhias profissionais judaicas que aqui aportavam. ${ }^{28}$

${ }^{22}$ CÔRTE, 2007, p. 133.

${ }^{23}$ O Bund (União Geral dos Trabalhadores Judeus na Lituânia, Polônia e Rússia), criado em 1897, preconizava a instauração do sistema socialista, com a manutenção da autonomia cultural de cada grupo nacional, inclusive dos judeus; foi enorme sua importância na evolução dos movimentos revolucionários da Rússia, tendo inclusive exercido papel de relevo na formação do Partido Operário Social-Democrata Russo (POSDR), que só se constituiu em março de 1898 e viria a se transformar, após sua divisão nas facções bolchevique e menchevique, em Partido Comunista da União Soviética (PCUS). Ettinger destaca que "não é coincidência que a primeira conferência do Partido tenha sido sediada em Minsk [atual capital da Bielo-Rússia], cidade da Região de Assentamento na qual o Bund operava, e este tenha colocado à disposição do Partido uma gráfica ilegal" (ETTINGER, 1997, p. 910).

${ }^{24}$ WALDMAN, 2010, p. 28.

${ }^{25}$ FALBEL, 2013, p. 275. Helena Lewin destaca que "grande parte desses imigrantes já havia iniciado sua atividade política em seus países de origem, majoritariamente no Bund - organização socialista judaica que lutava contra a discriminação no trabalho e no salário a que estavam submetidos os judeus da Europa Oriental - que, em muitas ocasiões, conglomerava-se em uma união nacional com os socialistas poloneses, o Polska Parti Socialistik. [...] O Bund, no Brasil, não conseguiu repetir sua pujança europeia, nem a força articuladora de recrutamento e ação e, assim, muitos desses imigrantes 'bundistas' passaram a compor o segmento comunista formal do Rio de Janeiro". (LEWIN, 2019, p. 225).

26 "Monumento vivo, Casa do Povo é um lugar onde lembrar é agir". Disponível em https://catracalivre.com.br/agenda/casa-do-povo-sp/. Acessado em 29/03/2020.

${ }^{27}$ Uriel Acosta nasceu Gabriel da Costa em 1585 no Porto como católico e emigrou para Amsterdã, onde retornou ao judaísmo, e morreu em abril de 1640. Racionalista e livre-pensador, tornou-se um exemplo entre os judeus de alguém martirizado pela intolerância de sua própria comunidade religiosa. Às vezes é citado como precursor do renomado filósofo Baruch Spinoza. Disponível em https://www.britannica.com/biography/Uriel-Acosta, acesso em 08/05/2020, tradução nossa.

${ }^{28}$ GUINSBURG, 2010, p. 11. 
A atividade teatral do Zukunft - e sucessores -, registre-se, não foi inaugural. De fato, já entre 1912 e 1914 havia teatro amador em ídiche, em São Paulo. Em 1914 foi formado o "Círculo PhiloDramático" junto à Biblioteca Israelita. ${ }^{29}$

Instrumento de preservação cultural de um grupo étnico, o teatro pode ser visto como um dos lugares de inscrição da identidade construída num idioma que acenava para o seu desaparecimento, uma vez que o período entre a imigração e o final da experiência teatral marca o declínio do ídiche. ${ }^{30}$ Por outro lado, registre-se que no Brasil nunca se chegou a criar um teatro estável como os que existiram em alguns países da Europa, Estados Unidos e Argentina. Ou seja, era comum que companhias e trupes se fizessem e desfizessem com facilidade. ${ }^{31}$

\section{Importância do Teatro Ídiche na cultura brasileira}

Desde os primórdios, os imigrantes que se dedicaram ao teatro ídiche buscaram integrar-se no ambiente da cultura da população hegemônica, numa via de duas mãos, ou seja, sem perda de sua peculiaridade judaica - falantes do ídiche -, absorver elementos do teatro brasileiro, como se viu acima em relação ao Teatro Escola, e, também, contribuir com este, aportando sua experiência europeia.

No depoimento aos autores, Hugueta Sendacz afirmou que não havia problemas de relacionamento com os não-judeus, sendo usual a manutenção de contato com intelectuais, escritores, autores, que sempre foram receptivos a essas trocas. Para enfatizar a abertura para a sociedade de acolhimento, basta lembrar, como visto acima, as inúmeras atividades não-judaicas abrigadas pela Casa do Povo, desde sua fundação.

A montagem de peças em português era outra das formas desse intercâmbio. Em várias ocasiões, as peças apresentadas visavam a um público mais amplo do que apenas a comunidade judaica, abordando temáticas universais. Já em 1948, por exemplo, houve um evento importante neste sentido. Segundo Hugueta Sendacz, naquele ano, portanto ainda na época do Centro Cultura $e$ Progresso, o Dram kraiz apresentou no Teatro Municipal a opereta $O$ sonho de Goldfaden, com lotação completa em três sessões (30/05, 06/06 e 13/06), e depois foi para Buenos Aires. Esta montagem foi dirigida por Jacob Rotbaum, que viera da Polônia com esse projeto.

Outras apresentações em locais públicos aconteceram, por exemplo, no I. E. Caetano de Campos em 10 de julho de 1949, e em 27 de março, novamente no Teatro Municipal com a peça Der dorfs yung ("O jovem aldeão"), em 18 de setembro com a peça Madame Jaclin e em 11 de dezembro com Di grine felder ("Campos verdejantes") ${ }^{32}$. Registre-se o amplo acesso que o grupo de teatro do Centro Cultura e Progresso tinha obtido para uso do Teatro Municipal de São Paulo, que dispõe de espaço para receber cerca de 1.500 espectadores.

Em 1956, em outra chave de participação na cultura de acolhimento, o ICIB montou a peça Bolinbrook \& Cia ou As casadas solteiras, de Martins Pena, e com esta montagem o grupo participou do $3^{\circ}$ Festival de teatro amador de São Paulo, tendo conquistado dois Arlequins - o prêmio de Melhor Ator para Boris Cipes e o de Melhor Coadjuvante Masculino para Elias Gleizer. No ano seguinte, participando de outra edição do mesmo Festival, apresentaram a peça Histórias para serem contadas, do autor argentino Osvaldo Dragun, e Ana Mauri conquistou o Arlequim de Melhor Atriz.

Este acesso a instalações públicas para apresentação de peças e eventos culturais para a população não judaica ocorreu também em outras capitais que abrigaram experimentos de teatro

\footnotetext{
${ }^{29}$ FALBEL, 2013, p. 283. Para Henrique Veltman, a "Sociedade Philodrammática" seria a mais antiga associação cultural judaica de São Paulo (VELTMAN, 1994, p. 79). Além disso, Egon e Frieda Wolff assinalam que por volta de 1923 integrantes da imigração russo-polonesa tentaram estabelecer um teatro em língua ídiche no salão Luso-Brasileiro, apresentando peças de Scholem Aleichem e Peretz. (WOLFF; WOLFF, 1988, p. 127-128).

${ }^{30}$ WALDMAN, 2010, p. 21.

${ }^{31}$ FALBEL, 2013, p. 26.

${ }^{32}$ FALBEL, 2013, p. 299.
} 
ídiche. Em Curitiba, por exemplo, já em 1923 foi apresentada a opereta histórica Bar Kochba, de Goldfaden, no Teatro Guayra. ${ }^{33}$ Nachman Falbel registra outro evento dessa natureza na mesma cidade:

um acontecimento histórico-literário que ocorreu em Curitiba, em 3 de outubro de 1926, quando se realizou um verdadeiro encontro cultural entre cristãos e judeus no Instituto Neo-Pitagórico, levando-se pela primeira vez ao conhecimento de um público brasileiro, em português, autores clássicos da literatura iídiche e hebraica. ${ }^{34}$

Note-se que um dos objetivos declarados do Centro Israelita do Paraná com a criação de um grupo de teatro era "provar à sociedade que a coletividade israelita do Paraná participa do esforço comum em prol da cultura do povo paranaense". 35

O mesmo aconteceu em Porto Alegre, com a apresentação de peças em ídiche no Teatro São Pedro, principal casa de espetáculos da capital gaúcha. Nas palavras de Ieda Gutfreind,

[a]s manifestações teatrais em língua ídiche representaram um elemento catalizador dos interesses identitários da comunidade judaica de Porto Alegre. Divulgadas em jornais locais e propagandeadas no interior da coletividade, as apresentações teatrais, sejam por parte de profissionais ou de amadores, no período a que a pesquisa se refere, lotavam o Teatro São Pedro, então o espaço cultural por excelência da capital do estado sulino, com capacidade aproximada para setecentos espectadores. ${ }^{36}$

Em relação a esta interpenetração entre as culturas, no caso do Rio de Janeiro, Nachman Falbel lembra carta de Zygmunt Turkow a Lasar Segall, datada de 29 de julho de 1945, convidando-o para projetar os figurinos e cenários de Dos groisse gevins ("A sorte grande"), de Scholem Aleichem:

Esse espetáculo, além de seu caráter comemorativo, deverá também servir como demonstração de nossas artes teatrais, pelas quais há tanto interesse nos círculos culturais brasileiros. É evidente que sua participação como criador dos projetos de cenário e figurino seria a garantia de um alto nível artístico para o espetáculo e uma celebração solene da cultura judaica no Brasil. ${ }^{37}$

A peça, também conhecida como 200.000, foi apresentada em 20 de novembro de 1945 no Teatro Ginástico do Rio de Janeiro. ${ }^{38}$

Outra influência do teatro ídiche na cultura brasileira, ainda em decorrência da atuação de Turkow, é assinalada por Paula Ribeiro e Susane Worcman e se refere a técnicas de representação. Segundo essas autoras, Turkow introduziu a leitura prévia do texto e a análise das personagens pelos atores, sentados em torno de uma mesa, antes dos ensaios em cena; Ribeiro e Worcman enfatizam que se tratava de uma técnica nova, pouco usual também no teatro brasileiro, que vivia ainda em torno dos grandes astros, absolutos no centro do palco, e em torno dos quais giravam as marcações. ${ }^{39}$ As mesmas pesquisadoras registram que

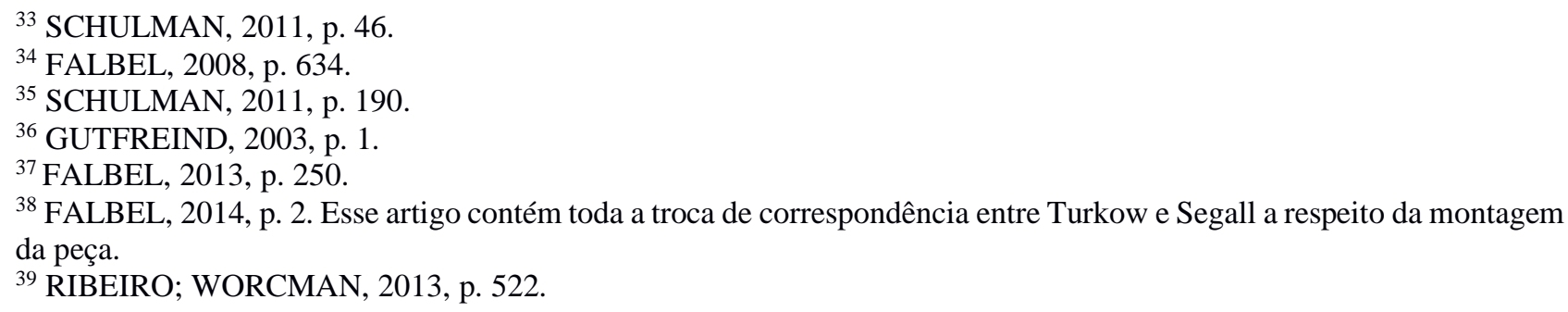


integrantes da vida teatral no Rio, apesar de não entenderem as falas, assistiam a ensaios, possivelmente interessados na técnica de Zygmunt Turkow, renomado diretor e ator do teatro ídiche polonẽs, que havia trazido da escola de Stanislavski novas formas de preparação do ator e de interpretação do texto teatral ${ }^{40}$. assinala:

Na sequência, Turkow viria a ter significativa participação no teatro brasileiro, como Falbel

De fato, nesse tempo, ele estaria atuando no teatro brasileiro e regeria com Os Comediantes a peça Mulher sem pecado de Nelson Rodrigues, encenada no Teatro Phoenix em janeiro de 1946, tendo como parceiro Ziembinski e como assistente João Angelo Labanca. Turkow seria admirado por sua direção mesmo antes da apresentação da peça e pelo próprio autor Nelson Rodrigues. Também seria o diretor e responsável pela encenação da peça Terras do Sem Fim, de Jorge Amado, com adaptação teatral de Graça Mello, apresentada no Teatro Ginástico em 8 de agosto de 1947, com cenários de Santa Rosa. ${ }^{41}$

\section{Decadência do Teatro Ídiche}

Como vimos, os primeiros eventos de teatro ídiche no Brasil aconteceram já na década de 1910; cresceram nos anos vinte e trinta do século XX, com o aumento do fluxo migratório; atingiram seu apogeu nos anos quarenta e cinquenta, e finalmente entraram em decadência nos anos sessenta e cessaram por completo nos anos setenta ${ }^{42}$, não obstante os esforços de seus ativistas no sentido de se integrarem no teatro brasileiro e interagirem com intelectuais e artistas ligados à cultura hegemônica do país.

Como e por que o teatro ídiche no Brasil terminou? Há um certo consenso em que o teatro ídiche apenas teria acompanhado o destino do idioma. O mameloschn, falado pelos imigrantes da Europa do leste, deixou de ser a língua de seus filhos nascidos aqui, que optaram pelo português. Os imigrantes, obtendo cidadania brasileira, buscaram plena integração na cultura local.

Para Berta Waldman, por exemplo, o teatro ídiche foi "o lugar de inscrição da identidade construída num idioma que acenava para o seu desaparecimento, uma vez que o período entre a imigração e o final da experiência teatral marca o declínio do ídiche". ${ }^{43}$

Nachman Falbel, tratando das comédias musicais em ídiche, vai na mesma direção ao referir que

com o passar do tempo e o falecimento desses atores cantores, tais apresentações artísticas tornar-se-iam cada vez mais raras. E isso se devia ao próprio fato de que o público mudara e o número dos que podiam entender o seu repertório diminuira gradativamente. ${ }^{44}$

Este pesquisador reporta ainda, em nota de rodapé, citando trecho do catálogo Stars, Strikes and the Yiddish Stage: The Story of the Hebrew Actors' Union, de 2009, que o mesmo aconteceu com o vigoroso teatro ídiche americano: "With the cessation of immigration, the Yiddish theater had been

${ }^{40}$ RIBEIRO; WORCMAN, 2012, p. 37. Disponível em: 〈https://issuu.com/premiata/docs/teatroidichebrasil〉, Acesso em: 03/03/2020.

${ }^{41}$ FALBEL, 2013, p. 257-258.

${ }^{42}$ Segundo Hugueta Sendacz, como vimos acima, a última peça encenada pelo Dram Kraiz de São Paulo, Di Ksube ("A certidão de casamento") aconteceu em novembro de 1965 (SENDACZ, s.d., p. 5).

${ }^{43}$ WALDMAN, 2010, p. 21.

${ }^{44}$ FALBEL, 2013, p. 226. 
gradually losing its audiences and Yiddish culture was being eroded by the current American life. Jewish audiences were drifting away to Broadway and the motion pictures". ${ }^{45}$ semelhantes:

Discorrendo sobre o teatro ídiche em Curitiba, Sara Schulman chega a explicações

Com o passar do tempo, os hábitos tradicionais foram desaparecendo, assim como o próprio idioma, e é provável que o teatro no idioma iídiche tenha deixado de ser utilizado, como veremos adiante, simplesmente pela natural evolução dos acontecimentos - circunstâncias que podem ser, afinal, compreendidas: com o decorrer do tempo, aqueles imigrantes tornaram-se participantes das atividades voltadas aos novos interesses. Obedecendo às novas situações e acompanhando o desenvolver de seus filhos, encaminharam-se aos poucos, pelas exigências quotidianas, para novas motivações. ${ }^{46}$

Em entrevista concedida à revista $O$ Macabeu em 1980, Chaim Israel Jugend pondera, melancolicamente, que "infelizmente, hoje são poucos os que se interessam ainda pelo teatro iídiche, além de que são muitos os que nem mais, sequer, entendem o idioma iídiche". ${ }^{47}$

Talvez a ascenção social e econômica dos judeus, reduzindo o apelo do ideário de esquerda e, portanto, da militância política, da luta social, também tenha contribuído para esse final.

Não obstante, a explicação oferecida por Hugueta Sendacz, no depoimento aos autores, diverge em parte desse consenso. Para ela, a decadência do teatro ídiche - que acabaria acontecendo de qualquer maneira -, foi precipitada pela instalação do regime militar em 1964; com medo da repressão, o público se afastou. Em 1970, o Scholem Aleichem foi desativado. Quando a democracia foi restabelecida, em 1985, o teatro não conseguiu se reerguer, o próprio uso do ídiche como idioma falado já tinha sido abandonado. Os filhos dos imigrantes falavam português e se integraram na cultura hegemônica.

Este estado de coisas é confirmado por matéria publicada no site Catraca Livre, com autoria atribuída à redação: durante a ditadura militar (1964-1985), a Casa do Povo se firmou como lugar de resistência cultural e política. Enquanto filhos e filhas de perseguidos políticos estudavam na escola com bolsas e nomes falsos, muitos espetáculos encenados no TAIB foram censurados e alguns professores, presos e torturados. ${ }^{48}$

Também Marcos Grinspum Ferraz aduz observações que vão ao encontro da interpretação de Hugueta Sendacz:

Com o golpe de 1964 e a instauração do regime militar, a Casa do Povo adentra um período conturbado de sua história. Enquanto o jornal Nossa Voz foi fechado pelo governo, a escola acolhia cada vez mais filhos de perseguidos políticos (incluindo muitos não judeus), que ganhavam bolsas e, se necessário, nomes falsos. Professores chegaram a ser presos e torturados e a Casa se tornou um polo de resistência à ditadura, especialmente através das atividades do TAIB. Nele foram encenadas peças do Teatro de Arena - de autores como Plínio Marcos e Augusto Boal - e do Teatro Popular do Sesi, entre outros. Ao mesmo tempo em que as apresentações lotavam o teatro e a escola seguia funcionando, muitos membros da comunidade judaica se

\footnotetext{
${ }^{45}$ FALBEL, 2013, p. 29. “Com a cessação da imigração, o teatro ídiche estava perdendo gradualmente seu público e a cultura ídiche estava sendo corroída pela vida americana atual. O público judeu estava se afastando para a Broadway e os filmes". (tradução nossa)

${ }^{46}$ SCHULMAN, 2011, p. 32.

${ }^{47}$ Apud SCHULMAN, 2011, p. 122.

48 "Monumento vivo, Casa do Povo é um lugar onde lembrar é agir". Disponível em: <https://catracalivre.com.br/agenda/casa-do-povo-sp>. Acesso em: 29/03/2020.
} 
afastaram, por medo de perseguição ou discordância ideológica, e as dificuldades financeiras aumentaram. ${ }^{49}$

Em suma, acreditamos que, a exemplo do que aconteceu na Europa, em Nova York e em Buenos Aires, o teatro ídiche viria a terminar, em consequência do arrefecimento do fluxo migratório, do abandono do idioma ídiche pelos imigrantes, pressionados por seus filhos a se comunicarem em português, pela plena integração das gerações nascidas no Brasil à cultura hegemônica e pela ascenção social e econômica dos imigrantes e seus descendentes.

Mas este final pode ter sido antecipado pela repressão policial aos ativistas de esquerda; ao clima de temor e insegurança implantado então; lembremos que já na época do Estado Novo, a famigerada Era Vargas, os judeus eram vistos como inimigos potenciais do regime, o que voltou a acontecer entre 1964 e 1985.

\section{Conclusões}

O título do abrangente e profundo livro de Nachman Falbel sobre o teatro ídiche no Brasil, Estrelas errantes, presta homenagem aos heróicos atores itinerantes, às troupes que se apresentavam em diversas cidades onde existiam comunidades falantes do ídiche, levando teatro de ótimo nível àquelas comunidades e fortalecendo as iniciativas de criação de grupos teatrais locais, na medida em que incorporavam em suas apresentações atores da propria cidade visitada, oferecendo-lhes oportunidades para ampliarem suas experiências cênicas e propiciando convívio com atores e diretores profissionais.

Talvez, no entanto, a expressão estrela errante possa se aplicar ao próprio teatro ídiche brasileiro que, como vimos, existiu por pouco mais do que meio século.

De fato, empreendimentos de imigrantes pobres, atores amadores que trabalhavam o dia todo em suas oficinas ou comércios ambulantes e que encontravam forças para se reunirem à noite para ensaiar a peça que estavam montando. Algumas vezes, o diretor podia ser um profissional remunerado, mas em geral atores, diretores e pessoal auxiliar eram voluntários que se quotizavam para atender às despesas das montagens.

Este teatro, que já era uma atividade frequente na Europa da qual os participantes fugiam, e que visava, no início, a manter os laços comunitários e ampliar as possibilidades de ativismo social e político, tornou-se cada vez mais ambicioso, com a montagem de peças de maior duração, de autoria de dramaturgos importantes, e se apresentando em salas de grande capacidade de público, como o Teatro Municipal de São Paulo e o Teatro São Pedro de Porto Alegre.

Um teatro que ofereceu contribuição expressiva à cultura teatral brasileira, participando de festivais, tratando em suas peças de temáticas de conteúdo social que extrapolavam o público judaico; um teatro do qual muitos atores sairam para continuar suas carreiras no teatro e na televisão brasileiros.

Mas era inevitável: o decréscimo no fluxo migratório, o abandono do ídiche como língua de expressão do dia a dia, a integração dos filhos e de muitos dos próprios imigrantes na cultura brasileira decretaram a decadência e o fim do teatro ídiche, fenômeno reforçado pela repressão imposta pelo regime que governou o país de 1964 a 1985 e pela ascenção social dos imigrantes, que, assim, se distanciavam da luta política e social à qual se dedicavam os grupos teatrais e as entidades

${ }^{49}$ FERRAZ, Marcos Grinspum. “Um lugar onde lembrar é agir”. In: Arte!Brasileiros, São Paulo, 10 de julho de 2019. Disponível em: <https://artebrasileiros.com.br/arte/instituicao/um-lugar-onde-lembrar-e-agir>. Acesso em 03/03/2020. 
mantenedoras. E, talvez, também pela cisão que ocorreu na Casa do Povo em 1957, quando Kruschev revelou ao mundo os crimes do estalinismo ${ }^{50}$.

Como resumem Susane Worcman e Paula Ribeiro, "um teatro que não tem mais nem artistas nem público, falado em uma língua fora de uso..." ${ }^{51}$.

A pergunta se impõe, então: é possível reviver o teatro ídiche de forma orgânica? O renascimento do teatro ídiche, acreditamos, enfrenta as mesmas dificuldades que o renascimento de seu suporte, o idioma ídiche. Em todo o mundo são feitos esforços no sentido de estudar o ídiche, sua gramática; grupos se reúnem para conversar em ídiche e traduzir suas obras literárias clássicas. ${ }^{52}$ Mas não temos conhecimento de que o ídiche tenha passado à condição de língua de expressão cotidiana de algum grupo de pessoas, excetuadas algumas comunidades ortodoxas que se recusam a conversar em hebraico por serem de opinião que esse idioma, língua santa, só pode ser utilizado em ambiente sinagogal, no serviço religioso.

\section{Referências}

CALVO, Júlia. Entre fazer a América e construir a cidadania: os judeus em Belo Horizonte nas primeiras décadas do século XX (1910-1940), Tese de doutorado, PUCMG, Belo Horizonte, 2014. CÔRTE, Andréa Telo da. "A ADAF e a memória dos judeus progressistas de Niterói - 1922-2005". In: LEWIN, Helena (org.), Judaísmo e modernidade: suas múltiplas inter-relações. Rio de Janeiro: H. Lewin, 2007.

ETTINGER, Shmuel. "The modern period". In: BEN-SASSON, Haim Hillel (org.) A history of the Jewish people. Cambridge: Harvard University Press, 1997.

FALBEL, Nachman. A comunidade judaica no Brasil. São Paulo: Federação Israelita do Estado de São Paulo, 1984.

FALBEL, Nachman. Judeus no Brasil. São Paulo: Humanitas, 2008.

FALBEL, Nachman. Estrelas errantes: memória do teatro ídiche no Brasil. Cotia: Ateliê Editorial, 2013.

FALBEL, Nachman. "Lasar Segall e Zygmunt Turkow: dos Groisse Gevins (a Sorte Grante)". In: Cadernos de Língua e Literatura Hebraica n. 11, 2014.

GARFINKEL, Miriam. "Uma fênix do Rio de Janeiro; um estudo de caso sobre a língua ídish ou de como ressignificar o OY VEY". In: LEWIN, Helena (org.). Judaísmo e globalização: espaços e temporalidades. Rio de Janeiro: 7Letras, 2010

GOUSSINSKY, Sonia. Era uma voz: o cantar ídiche, suas memórias e registros no Brasil. Tese de doutorado apresentada ao Programa de Pós-graduação em Estudos Judaicos e Árabes da Universidade de São Paulo, FFLCH, 2012.

GUINSBURG, Jacó. Aventuras de uma língua errante: ensaios de literatura e teatro ídiche. São Paulo: Perspectiva, 1996.

GUTFREIND, Ieda. "O espetáculo adquire novo ritmo e a história já é outra: as manifestações teatrais na coletividade judaica do Rio Grade do Sul 1930-1960". Texto apresentado à ANPUH, XXII Simpósio nacional de história - João Pessoa, 2003.

LESSER, Jeffrey. O Brasil e a questão judaica: imigração, diplomacia e preconceito. Tradução de Marisa Sanematsy. Rio de Janeiro: Imago, 1994.

RIBEIRO, Paula. Cultura, memória e vida urbana: judeus na Praça Onze, no Rio de Janeiro (19201980). Tese de doutorado - PUCSP, São Paulo, 2008.

RIBEIRO, Paula, WORCMAN, Susane (org.). Drama e Humor: Teatro ídiche no Brasil, 2012.

\footnotetext{
${ }^{50}$ No depoimento aos autores, Hugueta Sendacz recordou que "muitos dos diretores se afastaram, Alguns se tornaram inimigos, mesmo. Muito forte, muito violenta".

${ }^{51}$ RIBEIRO, WORCMAN, 2012, p. 13.

${ }^{52}$ Miriam Garfinkel, por exemplo, menciona um curso no âmbito da Associação Scholem Aleichem (ASA), cuja finalidade é congregar interessados em aprender a escrever e conversar em “mame-loschn” (GARFINKEL, 2010, p. 534).
} 
RIBEIRO, Paula, WORCMAN, Susane. "Drama e Humor. O teatro ídiche no Brasil”. In: LEWIN, Helena (org.). Judaísmo e Cultura: Fronteiras em movimento. Rio de Janeiro: Imprimatur, 2013.

SCHULMAN, Sara. $O$ teatro na vida da coletividade judaica curitibana: preservando a memória. Curitiba: Copygraf Gráfica e Editora Ltda., 2011.

SENDACZ, Hugueta. "Pequena trajetória do trabalho cultural, social e político realizado pelos dedicados imigrantes no Yugent Club, Dramkraiz, Centro de Cultura e Progresso, ICIB/Casa do Povo", inédito.

VELTMAN, Henrique. A história dos judeus em São Paulo. Rio de Janeiro: Consultor; Instituto Arnaldo Niskier: 1994.

WALDMAN, Berta. O teatro ídiche em São Paulo: memória. São Paulo: Casa Guilherme de Almeira: Annablume, 2010.

WOLFF, Egon, WOLFF, Frieda. Guia histórico da comunidade judaica de São Paulo. São Paulo: Editora B'nei B'rith, 1988. 